\title{
Neuromuscular electrical stimulation for preventing skeletal-muscle weakness and wasting in critically ill patients: a systematic review
}

\author{
Nicola A Maffiuletti ${ }^{1 *}$, Marc Roig ${ }^{2,3}$, Eleftherios Karatzanos ${ }^{4}$ and Serafim Nanas ${ }^{4}$
}

\begin{abstract}
Background: Neuromuscular electrical stimulation (NMES) therapy may be useful in early musculoskeletal rehabilitation during acute critical illness. The objective of this systematic review was to evaluate the effectiveness of NMES for preventing skeletal-muscle weakness and wasting in critically ill patients, in comparison with usual care.

Methods: We searched PubMed, CENTRAL, CINAHL, Web of Science, and PEDro to identify randomized controlled trials exploring the effect of NMES in critically ill patients, which had a well-defined NMES protocol, provided outcomes related to skeletal-muscle strength and/or mass, and for which full text was available. Two independent reviewers extracted data on muscle-related outcomes (strength and mass), and participant and intervention characteristics, and assessed the methodological quality of the studies. Owing to the lack of means and standard deviations (SDs) in some studies, as well as the lack of baseline measurements in two studies, it was impossible to conduct a full meta-analysis. When means and SDs were provided, the effect sizes of individual outcomes were calculated, and otherwise, a qualitative analysis was performed.
\end{abstract}

Results: The search yielded 8 eligible studies involving 172 patients. The methodological quality of the studies was moderate to high. Five studies reported an increase in strength or better preservation of strength with NMES, with one study having a large effect size. Two studies found better preservation of muscle mass with NMES, with small to moderate effect sizes, while no significant benefits were found in two other studies.

Conclusions: NMES added to usual care proved to be more effective than usual care alone for preventing skeletal-muscle weakness in critically ill patients. However, there is inconclusive evidence for its benefit in prevention of muscle wasting.

Keywords: Muscle strength, Muscle mass, Quadriceps femoris, Intensive care, Sepsis, Rehabilitation

\section{Background}

A large majority of patients admitted to the intensive care unit (ICU) after the very acute phase of a critical illness exhibit major defects in skeletal-muscle strength (weakness) and mass (wasting) [1-3]. This so-called ICU-acquired weakness (ICUAW) is generally defined as a bilateral deficit of muscle strength in all limbs [4], which is accompanied by a profound loss of muscle mass (as high as $5 \%$ per day during the first week of

\footnotetext{
* Correspondence: nicola.maffiuletti@kws.ch

'Neuromuscular Research Laboratory, Schulthess Clinic, Zurich, Switzerland Full list of author information is available at the end of the article
}

ICU stay [5,6]), and is associated with delayed weaning from mechanical ventilation [7], protracted and costly stays in ICU and hospital stay (the average daily ICU cost being approximately $€ 1,000$ [8]), and high mortality rates $[9,10]$. ICUAW, whose etiology is multi-factorial, is associated with impaired physical function and health status in patients who have spent time in ICU, which can persist even years after hospital discharge [11,12]. This drastically increases the duration of post-ICU treatments (including rehabilitation), and provokes severe social, psychological, and economic consequences (the average cost per life-year gained being approximately $€ 6,000$ 
[8]), thus affecting quality of life and delaying return to physical self-sufficiency and return to work of people who have been critically ill.

Because early rehabilitation/mobilization in the ICU has been shown to enhance short-term and potentially long-term functional outcomes [13-15], the use of physicaltherapy strategies to counteract skeletal-muscle weakness and wasting has been promoted frequently in the past few years [16-20]. Neuromuscular electrical stimulation (NMES), a technique that consists of generating visible muscle contractions with portable devices connected to surface electrodes [21], has been shown to be effective in treating impaired muscles [22] as it has the potential to preserve muscle-protein synthesis and prevent muscle atrophy during prolonged periods of immobilization [23]. ICU-based NMES has recently been introduced for the treatment of ICUAW, as it does not require active patient cooperation, has an acute beneficial systemic effect on muscle microcirculation [24], and seems to provide some structural and functional benefits to critically ill patients [25]. However, owing to the heterogeneity of the critically ill patient group and also of the NMES procedures implemented in ICUs [18,26-28], the effectiveness of this rehabilitation procedure for ICUAW prevention remains to be clearly proven.

Previous reviews have analyzed the effect of NMES on different muscle outcomes in patients with specific chronic diseases such as chronic obstructive pulmonary disease (COPD) [22]. Since those reviews were published, several randomized controlled trials (RCTs) have been completed. Furthermore, a detailed analysis of the effects of NMES in critically ill patients is lacking. Results from previous studies suggest that the most deconditioned patients obtain the best results when NMES is applied [22]. Given the potential use of NMES among patients with a limited capacity to engage in voluntary muscle work, assessment of the evidence for the use of NMES in critically ill patients is urgently needed. We therefore undertook a formal systematic review of the literature to determine the rehabilitative effect of NMES on skeletalmuscle strength and mass in critically ill patients, in comparison with standard care.

\section{Methods}

\section{Electronic search and information sources}

Although we developed a review protocol and followed Preferred Reporting Items for Systematic Reviews and Meta-Analyses (PRISMA) guidelines (see Additional file 1) [29], the study protocol was not registered. Two of the authors (EK, SN) independently performed the electronic search on the following databases: PubMed (1951 to present), Cochrane Controlled Trials Register (CENTRAL) (1894 to present), Cumulative Index to Nursing and Allied Health Literature (CINAHL) (1981 to present), Web of
Science (1970 to present) and Physiotherapy Evidence Database (PEDro) (1929 to present). Reference lists from articles related to the topic were also searched. The search was not language-restricted but it was limited to RCTs completed on human subjects. The terms used to perform the search were: electrotherapy, electrical stimulation, electrical muscle stimulation, electromyostimulation, electrostimulation, neuromuscular stimulation, and NMES. The results of the primary search were combined with the terms: critically ill patients, critical illness, intensive care, and ICU. For instance, these terms were combined as follows to build the search in PubMed: (electrotherapy OR electrical stimulation OR electrical muscle stimulation OR electromyostimulation OR electrostimulation OR neuromuscular stimulation OR NMES) AND (critically ill patients OR critical illness OR intensive care OR ICU). As additional filters, clinical trial (in 'Article types') and humans (in 'Species') were chosen. The latest electronic search was performed on March 3, 2012.

\section{Study selection and eligibility criteria}

The list of titles and abstracts of articles retrieved in the electronic search were first reviewed independently by two of the authors (EK, NAM), who selected only those potentially relevant for a more detailed review at full-text level. Both reviewers then read the full text and applied the following inclusion criteria: RCTs 1) exploring the effect of NMES in critically ill patients; 2) with a well-defined NMES protocol (that is, the main stimulation parameters were provided) for at least one intervention group; 3) with NMES applied to skeletal muscles with an intensity equal to or greater than motor threshold (that is, evoking a visible muscle contraction); 4) including outcomes related to muscle strength and/or mass; (5) and whose full text was available. After reviewing the articles and applying the inclusion criteria independently, both reviewers held a consensus meeting to compare their results and decide which articles should finally be included in the review. In cases of disagreement, a third reviewer (MR) was included in the discussion to reach a final consensus.

\section{Data collection process}

Two of the authors (EK, MR) independently extracted the data from the studies included in the review. Data retrieved included characteristics of patients (number, gender, age, diagnosis, and disease severity), interventions (type, duration, frequency, and NMES parameters), and muscle-related outcomes. When provided, details on the number of patients excluded or discharged and their compliance with treatment were also recorded. After extraction, both reviewers compared their data-extraction sheets to confirm the accuracy of the data. 


\section{Methodological quality}

Two authors (EK and MR independently) assessed the methodological quality of the studies using the PEDro scale. This scale, which has been used extensively in the methodological evaluation of similar studies [22], and has previously shown good validity and reliability [30,31], is based on 11 items for assessing scientific rigor: eligibility criteria, random allocation, concealed allocation, baseline comparability, blinded subjects, blinded therapists, blinded assessors, follow-up, intention-to-treat (ITT), betweengroup analysis, both point estimates, and variability. Ten of the items were used in this study to calculate the final score (maximum 10 points). The one item not used was eligibility criteria, which was excluded because it affects external but not internal or statistical validity. We compiled an arbitrary scale of quality, based on PEDro score, with high quality being a score greater than 5 , moderate quality being 4 or 5 , and low quality being 3 or lower [32]. To minimize errors and potential biases in the methodological evaluation, both reviewers compared their scores in a consensus meeting. In cases of disagreement, a third reviewer (NAM) was included in the discussion to reach a final consensus. Consistency between the two reviewers who performed the methodological assessment (PEDro scores) was evaluated with the Cronbach's coefficient $\alpha$. Overall methodological quality based on the PEDro scores was also categorized in accordance with the indications provided by Van Tulder et al. [33].

\section{Data analysis}

Outcomes were grouped into two main categories for data analysis: muscle strength and muscle mass (thickness and volume). Probably because data were not normally distributed, the majority of the studies included in the review reported continuous outcomes using medians with interquartile range instead of means with standard deviation (SD). We used several statistical approaches [34] in an attempt to normalize data distribution for the three studies that had raw data available $[25,35,36]$, but we failed to alter the skewed data distribution. We also used the equations proposed by Hozo et al. to estimate means and SDs from medians, range, and sample size [37]. However, none of these approaches allowed us to calculate means and SDs reliably. In addition, because of the critical status of some of the study participants, muscle strength was not assessed at admission, and therefore baseline strength measurements were not obtained in two studies [35,36]. Given these two important limitations, it was not possible to pool the data from the different studies to conduct a full meta-analysis. Instead, when means and SDs were provided, we calculated the effect size $(d)$ of individual outcomes by dividing the difference between mean change scores (post-intervention minus pre-intervention scores) by the pooled SD [38]. Effect sizes were then categorized in accordance with the criteria established by Cohen as large $(d>0.8)$, moderate $(d<0.8$ but $>0.2)$, or small $(d<0.2)$ effects [38]. When means and SDs at baseline and after the intervention were not provided, individual effect sizes were not calculated and, instead, a qualitative analysis of the data was performed.

\section{Results}

\section{Study selection}

The different steps of the electronic search are illustrated in Figure 1. The initial search yielded 461 articles, which were included in the review process at abstract level. After 113 duplicates were removed and 348 records were screened, only ten full-text articles could be assessed for eligibility (336 records were excluded because they did not meet all the required inclusion criteria, and two further studies were excluded because they were conference proceeding abstracts and the full text was not available $[39,40])$. Of those ten articles, two were excluded; one was not an RCT [41], and the other did not report any relevant muscle-related outcome [42]. Finally, the remaining eight RCTs met all the required criteria and were included in the systematic review [25,35,36,43-47]. It should be noted, however, that one of the selected articles [35] presented a secondary analysis of the same study reported in another article [36]; however, because these two studies reported data from different outcomes, we presented them individually $[35,36]$.

\section{Methodological quality}

The PEDro score for each study is reported in Table 1. The mean \pm SD PEDro score of the studies included in the review was $5.5 \pm 1.5$, with scores ranging from 4 to 8 (that is, moderate to high quality). When PEDro scores of the two reviewers were compared, consistency was high $(\alpha=0.751 ; \quad P<0.0001)$ [48]. The most common methodological weaknesses of the studies referred to the blinding of patients (although sham NMES was used in two studies $[43,44]$, which could be considered a type of blinding), therapists, and assessors. The allocation of subjects to different intervention groups was concealed in only two studies $[43,46]$. In addition, two studies did not report baseline data for muscle strength, and therefore comparability between groups could not be established $[35,36]$. Only three studies met the follow-up criteria as established by the PEDro scale $[43,45,46]$, either because data for at least one key outcome were not obtained in more than $15 \%$ of the patients initially allocated into treatment groups $[25,35,36]$, or because the number of patients from whom key outcome data were obtained was not explicitly stated $[44,47]$. Two of the studies used ITT analysis [35,36], and in one study all patients received treatments as allocated [46]. The rest of the studies did not meet the ITT analysis criterion [25,43-45,47]. The 


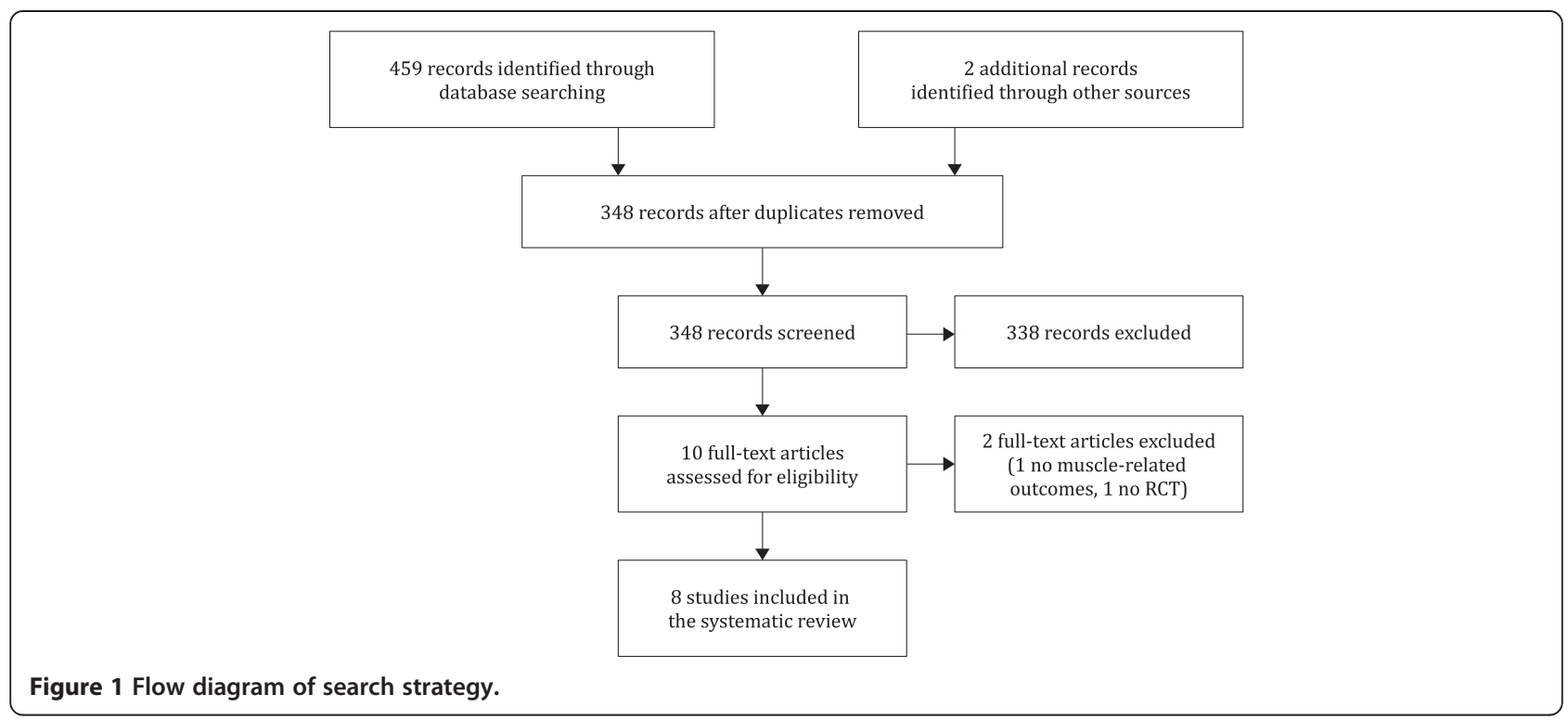

results of all five RCTs that investigated the effect of NMES on muscle strength supported the effectiveness of this intervention. Because two of these studies $[43,46]$ were of high methodological quality (PEDro score $\geq 7$ ), the level of evidence could be categorized as moderate to strong. By contrast, because only two [25,44] of the four studies that investigated the effect of NMES on muscle mass found a positive outcome, the evidence in support of this technique to improve muscle mass can be considered as conflicting.

\section{Participants}

Characteristics of the patients included in the review are shown in Table 2. We included in the review (at the study level) only that information on patients for whom data for at least one of the outcomes of interest was provided. Data from 172 patients (46 female, 126 male) were retrieved. Of those 172 patients, 74 were allocated to the NMES group and 76 to the control group, while the remaining 22 patients received NMES on one side of the body and the contralateral side acted as control. The most

Table 1 Methodological quality of the studies included in the systematic review (PEDro scores)

\begin{tabular}{|c|c|c|c|c|c|c|c|c|}
\hline & $\begin{array}{l}\text { Abdellaoui et al. } \\
2011 \text { [42] }\end{array}$ & $\begin{array}{l}\text { Gerovasili et al. } \\
2009 \text { [25] }\end{array}$ & $\begin{array}{l}\text { Gruther et al. } \\
2010 \text { [43] }\end{array}$ & $\begin{array}{l}\text { Karatzanos } \\
\text { et al. } 2012 \text { [34] }\end{array}$ & $\begin{array}{l}\text { Poulsen et al. } \\
2011 \text { [44] }\end{array}$ & $\begin{array}{l}\text { Rodríguez et al. } \\
2011 \text { [45] }\end{array}$ & $\begin{array}{l}\text { Routsi et al. } \\
2010 \text { [35] }\end{array}$ & $\begin{array}{l}\text { Zanotti et al. } \\
2003 \text { [46] }\end{array}$ \\
\hline $\begin{array}{l}\text { Random } \\
\text { allocation }\end{array}$ & $\checkmark$ & $\checkmark$ & $\checkmark$ & $\checkmark$ & $\checkmark$ & $\checkmark$ & $\checkmark$ & $\checkmark$ \\
\hline $\begin{array}{l}\text { Concealed } \\
\text { allocation }\end{array}$ & $\checkmark$ & & & & & $\checkmark$ & & \\
\hline $\begin{array}{l}\text { Baseline } \\
\text { comparability }\end{array}$ & $\checkmark$ & $\checkmark$ & $\checkmark$ & & $\checkmark$ & $\checkmark$ & & $\checkmark$ \\
\hline $\begin{array}{l}\text { Blinded } \\
\text { subjects }\end{array}$ & $\checkmark$ & & $\checkmark$ & & & & & \\
\hline \multicolumn{9}{|l|}{$\begin{array}{l}\text { Blinded } \\
\text { therapists }\end{array}$} \\
\hline $\begin{array}{l}\text { Blinded } \\
\text { assessors }\end{array}$ & & $\checkmark$ & $\checkmark$ & & $\checkmark$ & $\checkmark$ & & \\
\hline Follow-up & $\checkmark$ & & & & $\checkmark$ & $\checkmark$ & & \\
\hline $\begin{array}{l}\text { Intention-to- } \\
\text { treat }\end{array}$ & & & & $\checkmark$ & & $\checkmark$ & $\checkmark$ & \\
\hline $\begin{array}{l}\text { Between-group } \\
\text { analysis }\end{array}$ & $\checkmark$ & $\checkmark$ & $\checkmark$ & $\checkmark$ & $\checkmark$ & $\checkmark$ & $\checkmark$ & $\checkmark$ \\
\hline $\begin{array}{l}\text { Point estimates } \\
\text { and variability }\end{array}$ & $\checkmark$ & $\checkmark$ & $\checkmark$ & $\checkmark$ & $\checkmark$ & $\checkmark$ & $\checkmark$ & $\checkmark$ \\
\hline Total score & $7 / 10$ & $5 / 10$ & $6 / 10$ & $4 / 10$ & $6 / 10$ & $8 / 10$ & $4 / 10$ & $4 / 10$ \\
\hline
\end{tabular}

PEDro, Physiotherapy Evidence Database. 
Table 2 Characteristics of the patients included in the systematic review

\begin{tabular}{|c|c|c|c|c|c|c|c|}
\hline \multirow[t]{2}{*}{ Study } & \multirow{2}{*}{$\begin{array}{l}\text { Sample size }{ }^{a} \\
\text { (\% men) }\end{array}$} & \multirow[t]{2}{*}{ Age, years $^{b}$} & \multirow[t]{2}{*}{ Diagnoses } & \multicolumn{4}{|c|}{ Disease severity ${ }^{\mathbf{b}}$} \\
\hline & & & & SAPS III & SOFA & APACHE III & Other \\
\hline \multirow[t]{2}{*}{ Abdellaoui et al. [42] } & C: 6 (100\%) & C: 67(59-72) & COPD & & & & C: $\mathrm{FEV}_{1}$ of $15(10-27) \%$ \\
\hline & $\mathrm{N}: 9$ (78\%) & $N: 59(57-69)$ & & & & & $\mathrm{N}: \mathrm{FEV}_{1}$ of $25(17-41) \%$ \\
\hline \multirow[t]{3}{*}{ Gerovasili et al. [25] } & C: 13 (62\%) & C: 56(19) & Sepsis & $C: 61(14)$ & C: $8(3)$ & C: $18(6)$ & \\
\hline & $\mathrm{N}: 13(46 \%)$ & $N: 59(23)$ & Trauma & $\mathrm{N}: 66(9)$ & $\mathrm{N}: 10(3)$ & $\mathrm{N}: 19(3)$ & \\
\hline & & & Neurologic & & & & \\
\hline \multirow[t]{5}{*}{ Gruther et al. [43] } & $C(A): 9(89 \%)$ & $C(A): 48(12)$ & Polytrauma & & & & \\
\hline & $\mathrm{N}(\mathrm{A}): 8(88 \%)$ & $N(A): 52(10)$ & Cardiovascular & & & & \\
\hline & $C(\mathrm{~L}): 8(50 \%)$ & $C(L): 64(8)$ & Transplant & & & & \\
\hline & $\mathrm{N}(\mathrm{L}): 8(88 \%)$ & $\mathrm{N}(\mathrm{L}): 61(10)$ & Pneumonia & & & & \\
\hline & & & Cancer & & & & \\
\hline \multirow{5}{*}{$\begin{array}{l}\text { Karatzanos et al. [34] } \\
\text { and Routsi et al. [35] }\end{array}$} & C: $28(79 \%)$ & C: $59(21)$ & Sepsis & C: $58(14)$ & C: $8(3)$ & C: 19(5) & C: $39 \%$ with CIPNM \\
\hline & $\mathrm{N}: 24(79 \%)$ & $N: 55(20)$ & Trauma & $N: 55(11)$ & $\mathrm{N}: 8(3)$ & $\mathrm{N}: 16(4)$ & N: $13 \%$ with CIPNM \\
\hline & & & Post-surgery & & & & \\
\hline & & & Brain injury & & & & \\
\hline & & & Respiratory failure & & & & \\
\hline Poulsen et al. [44] & C/N: 8 (100\%) & $\mathrm{C} / \mathrm{N}:$ 67(64-72) & Sepsis & & C/N: 11(9-14) & C/N: 25(20-29) & $\begin{array}{l}\mathrm{C} / \mathrm{N}: 13(10-22) \text { days } \\
\text { in ICU }\end{array}$ \\
\hline Rodríguez et al. [45] & C/N: 14 (50\%) & C/N: 72(63-80) & Sepsis & & $\mathrm{C} / \mathrm{N}: 10(9-12)$ & C/N: 20(18-27) & $\begin{array}{l}\text { C/N: } 27(19-44) \text { days } \\
\text { in ICU }\end{array}$ \\
\hline \multirow[t]{2}{*}{ Zanotti et al. [46] } & C: 12 (67\%) & C: $65(4)$ & COPD & & & & C: 47(19) days in ICU \\
\hline & $\mathrm{N}: 12(75 \%)$ & $\mathrm{N}: 66(8)$ & & & & & $\mathrm{N}: 52(15)$ days in ICU \\
\hline
\end{tabular}

A, acute; APACHE III, Acute Physiology and Chronic Health Evaluation III; C, control group; CIPNM, critical illness polyneuromyopathy; COPD, chronic obstructive pulmonary disease; FEV 1 , forced expiratory volume in 1 second; ICU, intensive care unit; L, long-term; N, neuromuscular electrical stimulation group; SAPS III, Simplified Acute Physiology Score III; SOFA, Sequential Organ Failure Assessment.

${ }^{a}$ Only patients included in the analysis of the outcomes of interest are shown.

${ }^{b}$ Data are provided as means (standard deviation) or medians (interquartile range).

'The contralateral side acted as control.

common diagnoses at admission were sepsis, COPD, and trauma, although patients were also hospitalized because of neurological problems, cancer, or post-surgery complications. The severity of the disease was categorized by the Simplified Acute Physiology Score III (SAPS III) $[25,35,36]$, the Sequential Organ Failure Assessment (SOFA), and the Acute Physiology and Chronic Health Evaluation II (APACHE II) [25,35,36,45,46]. No severity scores were reported in one study [44]. In addition, two studies reported the number of patients diagnosed with critical illness polyneuromyopathy [35,36], and three other studies reported the number of days in the ICU [45-47]. Two studies that investigated the effects of NMES on patients with COPD reported spirometry and blood gas values as measures of disease severity [43,47]. According to international guidelines [49], those patients would be categorized as patients with severe to very severe COPD.

\section{Interventions}

The characteristics of the interventions are shown in Table 3. The duration of the NMES protocol ranged from 7 days to 6 weeks. Patients in the control group received usual care and, in some studies, either assisted limb mobilization with [43] or without sham NMES [47], or sham NMES alone [44]. NMES was delivered while the patient was relaxed, and targeted the following muscle groups: glutei [47], quadriceps [25,35,36,43-47], hamstrings [43], peroneus longus [25,35,36], and biceps brachii [46]. Specific details of the stimulation parameters are shown in Table 3. In all studies, the criterion to establish the minimum intensity of NMES was a visible muscle contraction, which corresponds to the motor threshold [50]. NMES intensity during the treatment was progressively adjusted to the individual patient's tolerance or set as a percentage (150\%) of the motor threshold [45]. Stimulation frequencies ranged from 8 to $100 \mathrm{~Hz}$, and pulse durations from 250 to $400 \mu \mathrm{s}$. Five studies reported the use of symmetric biphasic pulses [25,35,36,43,46], and one reported the use of asymmetric currents [47]. The shape (rectangular) of the stimulation pulse and the ramp-up and ramp-down times were reported in only three studies $[35,36,45]$. In general, compliance (percentage of sessions completed) with NMES treatment was high (81 to 100\%), but compliance was not reported in two studies $[44,47]$. No adverse events or complications in relation to NMES safety or tolerability were reported in 
Table 3 Intervention characteristics, outcomes and main results of the studies included in the systematic review

\begin{tabular}{|c|c|c|c|c|c|}
\hline \multirow[t]{2}{*}{ Study } & \multicolumn{2}{|c|}{ Interventions by group/side } & \multirow[t]{2}{*}{ NMES parameters } & \multirow[t]{2}{*}{ Outcomes $^{\mathrm{a}}$ (tools) } & \multirow[t]{2}{*}{ Main results } \\
\hline & $\mathrm{C}$ & $\mathbf{N}$ & & & \\
\hline \multirow[t]{3}{*}{ Abdellaoui et al. [42] } & \multirow{3}{*}{$\begin{array}{l}\text { ALM + sham NMES to quadriceps } \\
\text { and hamstrings }\end{array}$} & \multirow{3}{*}{$\begin{array}{l}\text { ALM }+ \text { NMES to quadriceps and } \\
\text { hamstrings (BL): } 60 \mathrm{~min} / \text { day } \times 5 \\
\text { days } / \text { week } \times 6 \text { weeks }\end{array}$} & Frequency: $35 \mathrm{~Hz}$ & \multirow{3}{*}{$\begin{array}{l}\text { Muscle strength } \\
\text {-(dynamometry) }\end{array}$} & \multirow{3}{*}{$\begin{array}{l}\text { Quadriceps strength increased more for } \\
N \text { than } C(p<0.01)\end{array}$} \\
\hline & & & Pulse duration: $400 \mu \mathrm{s}$ & & \\
\hline & & & $\begin{array}{l}\text { Intensity: } 15-32 \mathrm{~mA} \text { for quadriceps, } \\
22-47 \mathrm{~mA} \text { for hamstrings (start-end) }\end{array}$ & & \\
\hline \multirow[t]{4}{*}{ Gerovasili et al. [25] } & \multirow[t]{4}{*}{ Usual care } & \multirow{4}{*}{$\begin{array}{l}\text { Usual care }+ \text { NMES to quadriceps } \\
\text { and peroneus longus }(\mathrm{BL}): 55 \\
\text { min/day } \times 8 \text { days }\end{array}$} & Frequency: $45 \mathrm{~Hz}$ & \multirow[t]{4}{*}{ Muscle thickness (US) } & \multirow{4}{*}{$\begin{array}{l}\text { Rectus femoris and vastus intermedius } \\
\text { (right side) thickness decreased less } \\
\text { for } \mathrm{N} \text { than } C(p<0.05) ; d=0.11-0.39 \\
\text { (small-moderate) }\end{array}$} \\
\hline & & & Pulse duration: $400 \mu \mathrm{s}$ & & \\
\hline & & & On-off ratio: $12-6 \mathrm{~s}$ & & \\
\hline & & & Intensity: 37-38 mA (mean) & & \\
\hline \multirow[t]{4}{*}{ Gruther et al. [43] } & \multirow[t]{4}{*}{ Sham NMES } & \multirow{4}{*}{$\begin{array}{l}\text { NMES to quadriceps (BL): } 30-60 \\
\mathrm{~min} / \text { day } \times 5 \text { days/week } \times 4 \text { weeks }\end{array}$} & Frequency: $50 \mathrm{~Hz}$ & \multirow[t]{4}{*}{ Muscle thickness (US) } & \multirow{4}{*}{$\begin{array}{l}\text { Quadriceps thickness increased only } \\
\text { for N (long-term patients) }(p<0.13) \text {; } \\
d=0.36 \text { (moderate) }\end{array}$} \\
\hline & & & Pulse duration: $350 \mu \mathrm{s}$ & & \\
\hline & & & On-off ratio: 8-24 s & & \\
\hline & & & Intensity: tolerance & & \\
\hline \multirow[t]{4}{*}{ Karatzanos et al. [34] } & \multirow[t]{4}{*}{ Usual care } & \multirow{4}{*}{$\begin{array}{l}\text { Usual care }+ \text { NMES to quadriceps } \\
\text { and peroneus longus }(\mathrm{BL}): \\
55 \mathrm{~min} / \text { day } \times 7 \text { days/week } \\
\text { until ICU discharge }\end{array}$} & Frequency: $45 \mathrm{~Hz}$ & \multirow[t]{4}{*}{ Muscle strength (MRC) } & \multirow{4}{*}{$\begin{array}{l}\text { MRC scores for wrist flexion, hip flexion, } \\
\text { ankle dorsiflexion }(p<0.05) \text { and knee } \\
\text { extension }(p<0.01) \text { were greater for } \\
\mathrm{N} \text { than } \mathrm{C}\end{array}$} \\
\hline & & & Pulse duration: $400 \mu \mathrm{s}$ & & \\
\hline & & & On-off ratio: $12-6 \mathrm{~s}$ & & \\
\hline & & & Intensity: motor threshold & & \\
\hline \multirow[t]{5}{*}{ Poulsen et al. [44] } & \multirow{5}{*}{$\begin{array}{l}\text { Contralateral side acted } \\
\text { as control }\end{array}$} & \multirow{5}{*}{$\begin{array}{l}\text { NMES to quadriceps (UL): } 60 \\
\mathrm{~min} / \text { day } \times 7 \text { days }\end{array}$} & Frequency: $35 \mathrm{~Hz}$ & \multirow[t]{5}{*}{ Muscle volume (CT) } & \multirow{5}{*}{$\begin{array}{l}\text { Quadriceps volume decreased for both } \\
\text { C and N, with no difference between } \\
\text { sides }(p=0.1)\end{array}$} \\
\hline & & & Pulse duration: $300 \mu \mathrm{s}$ & & \\
\hline & & & On-off ratio: $4-6 s$ & & \\
\hline & & & Intensity: motor threshold & & \\
\hline & & & $+50 \%$ (adjusted daily) & & \\
\hline Rodríguez et al. [45] & Contralateral side acted & NMES to biceps brachii and & Frequency: $100 \mathrm{~Hz}$ & Muscle strength (MRC) & MRC scores for elbow flexion $(p=0.005)$ \\
\hline & as control & $\begin{array}{l}\text { quadriceps (UL): } 2 \times 30 \\
\mathrm{~min} / \text { day } \times 13 \text { days }\end{array}$ & Pulse duration: $300 \mu \mathrm{s}$ & & $\begin{array}{l}\text { and knee extension }(p=0.034) \text { were } \\
\text {-greater for } N \text { than C. Biceps thickness }\end{array}$ \\
\hline & & & On-off ratio: $2-4 \mathrm{~s}$ & Muscle thickness (US) & was unchanged \\
\hline & & & Voltage: $20-200 \mathrm{~V}$ & & \\
\hline Routsi et al. [35] & Usual care & Usual care + NMES to quadriceps & Frequency: $45 \mathrm{~Hz}$ & Muscle strength (MRC) & Global MRC score was greater for $\mathrm{N}$ \\
\hline & & $\begin{array}{l}\text { and peroneus longus (BL): } \\
55 \text { min/day } \times 7 \text { days/week }\end{array}$ & Pulse duration: $400 \mu \mathrm{s}$ & & \\
\hline & & until ICU discharge & On-off ratio: $12-6 \mathrm{~s}$ & & \\
\hline & & & Intensity: motor threshold & & \\
\hline Zanotti et al. [46] & ALM: 5 days/week $\times 4$ weeks & ALM + NMES to quadriceps & Frequency: 8-35 Hz & Muscle strength (MRC) & MRC score increased more for $\mathrm{N}$ than \\
\hline & & $\begin{array}{l}\text { and glutei (BL): } 25-30 \\
\mathrm{~min} / \text { day } \times 5 \text { days } / \text { week } \times 4 \text { weeks }\end{array}$ & Pulse duration: $250-350 \mu \mathrm{s}$ & & $C(p<0.02) ; d=1.44$ (large) \\
\hline & & & Intensity: motor threshold & & \\
\hline
\end{tabular}

ALM, active limb mobilization; BL, bilateral; C, control group; MRC, Medical Research Council; N, NMES group; NMES, neuromuscular electrical stimulation; US, ultrasonography. 
seven of the eight studies included in the systematic review [45]. For the remaining study, superficial skin burns and excessive pain occurred in one and two patients, respectively, out of fourteen patients treated by Rodriguez et al. [46].

\section{Outcomes}

\section{Muscle strength}

Five studies assessed the effects of NMES on strength of different muscle groups (Table 3) [35,36,43,46,47]. Four studies evaluated muscle strength using the Medical Research Council (MRC) scale [35,36,46,47]. One study found a significantly larger MRC score increase in the NMES group compared with the control group [47], with a large effect size $(d=1.44)$. Two studies reported greater MRC scores in the NMES group than in the control group [35,36], although baseline measurements were not provided. Another study found significantly higher MRC scores on the stimulated side compared with the contralateral side [46]. One study, in which quadriceps muscle strength was assessed by dynamometry [43], reported a significantly larger strength increase in the NMES group compared with the control group.

\section{Muscle mass}

Four studies assessed the effects of NMES on muscle thickness [25,44,46], or volume [45] (Table 3). Muscle thickness was measured with ultrasonography, and muscle volume was obtained from the analysis of computed tomography images. In one study, muscle thickness decreased less in the NMES group than in the control group [25], and effect sizes $(d)$ ranged from 0.11 to 0.39 , depending on the muscle group assessed. Another study investigated the effects of NMES on quadriceps muscle thickness in acute (less than 7 days hospitalization) and long-term (greater than 14 days hospitalization) patients, and found that thickness increased only for long-term patients $(d=0.36)$ but not for acute or sham patients [44]. The two other studies found no significant changes in muscle thickness between the stimulated and contralateral biceps brachii [46], and no differences in muscle volume loss between the stimulated and contralateral quadriceps [45].

\section{Discussion}

Neuromuscular electrical stimulation added to usual care, in comparison with usual care alone or sham stimulation, was associated with better muscle-strength outcomes in patients in the ICU, with moderate to strong evidence. However, the level of evidence was weaker and conflicting for outcomes related to muscle mass, with small to moderate effect sizes or no effect. These findings suggest that NMES may have the potential to prevent skeletalmuscle weakness in critically ill patients, which could confer many important physical, psychosocial, and economic benefits for these patients after discharge from ICU. However, it remains to be ascertained whether NMES therapy can also prevent the muscle wasting associated with critical illness.

The high inconsistency in ICU patient characteristics between studies was not unexpected (as attested by non-normal data distribution and lack of means and SDs), but it affected the methodological quality of the included studies, which prevented us from completing a metaanalysis. Therefore, the main results of this systematic review could only be interpreted with a thorough qualitative analysis. Although it is extremely challenging to perform large and well-controlled RCTs in this patient population, future NMES studies should consider stratifying patients for main diagnosis and eventually also for disease severity, as this latter feature has been identified as an independent risk factor for ICUAW incidence [10,51]. It is conceivable that the benefits of NMES are greater for patients admitted to the ICU with respiratory complications (as suggested by the large effect sizes for patients with COPD) [47], or neurological complications, compared with patients with sepsis or trauma. For example, inflammation-mediated electrolyte changes and also edema may seriously affect conductivity and thus electrical current diffusion [52], which could lessen any systemic effect of NMES in these patient samples.

The questionable validity and heterogeneity of the NMES protocol characteristics adopted in the eight studies included in this systematic review further complicated the interpretation of the present results. The strength of the contraction induced by NMES (that is, evoked tension), which is the main determinant of NMES effectiveness [53], was not reported in any of the included studies. Quantifying this parameter, rather than stating simple current intensity/voltage, is crucial as it would also permit discrimination of responders from non-responders [54,55], and eventually allows ascertainment of the optimal NMES characteristics for patients in the ICU on an individual basis. In addition, evoked tension should be maximized, whenever possible, by selecting appropriate current parameters (stimulation frequency of 50 to $100 \mathrm{~Hz}$ [56] and highest tolerable stimulation intensity, while minimizing fatigue with long relaxation phases), joint position (long muscle length), and methodological precautions such as the accurate determination of muscle motor points [57].

Assessing voluntary muscle strength in the ICU is extremely difficult. Despite potential limitations of manual muscle testing such as poor validity and inaccuracy of subjective ratings [58,59], especially when assessors are not blinded, evaluation of voluntary strength using the MRC score was used in the majority of the included RCTs, and only one study used dynamometry [43]. Considering the limited or absent cooperation of patients at admission into the ICU, and the considerable influence of central 
factors (including motivation) on maximal voluntary efforts [60], it would be preferable if evaluation of muscle function in these patients relied on artificially-evoked muscle responses. Therefore, alternative methods that are independent of patient cooperation such as peripheral magnetic stimulation (which can also be used to evaluate respiratory muscle function) [61], electrical impedance myography [62], myotonometry [63], and mechanomyography [64], would improve the validity of muscle testing in ICU.

The major risk factors for ICUAW are immobilization, multiple organ failure, systemic inflammatory response syndrome, gram-negative septicemia [10], hyperglycemia $[3,65]$, and medications such as aminoglycosides, colistin, and corticosteroids. All these elements should be viewed as important confounding factors that might distort accurate interpretations of our findings. For example, patients with a recent exacerbation of COPD (most of whom are prescribed corticosteroids, which can induce myopathy) were excluded in one instance [47], whereas another study examined the effects of NMES after COPD exacerbation (some patients received corticosteroids) [43]. Studies must always carefully control for immobilization days, disease severity scores (organ specific and physiological), and medication use.

Even though physical-therapy practices vary widely between different ICUs, there is growing interest in early rehabilitation strategies that have the potential to prevent skeletal-muscle weakness and wasting in critically ill patients [20]. These interventions range from passive stretching [5] and early mobilization therapy [3] to bedside cycling ergometry [13]. Interestingly, NMES added to usual care has recently been shown to be effective in reducing ICUAW incidence [36]. The present systematic review confirms these preliminary findings, highlighting the potential role of NMES as a preventive countermeasure against ICUAW. Compared with other rehabilitation strategies, the unique aspects of NMES are that it is relatively cost-effective (one multiple-user NMES unit costs less than $€ 400)$, does not require patient cooperation (it can be applied to sedated patients) or stable cardiac or respiratory function, can be implemented during the first few days after ICU admission, and provokes considerable central effects, both acute and chronic [66], which could also contribute to preventing the occurrence of muscle weakness in critically ill patients. Moreover, in addition to muscle-related outcomes, NMES has been shown to be more effective than conventional care or sham stimulation for improving pulmonary function [36,43,47], including accelerated weaning from mechanical ventilation [36], physical function (6-minute walking distance [43] and bed to chair transfer [47]), and for reducing the incidence of critical illness polyneuromyopathy [36]. However, the effects of NMES on the pathophysiological mechanisms of ICUAW are poorly known, and NMES cannot be easily used with all critically ill patients (for example, those with skin lesions, traumatic fractures, complete lower motor-neuron lesions and cardiac pacemakers), so that there is still no consensus among intensive care specialists about its real value.

\section{Limitations}

The major limitation of the present review concerns the unavailability of outcome data (for example, baseline strength measurements) to allow a full meta-analysis to be conducted. At face value, this lack of data could be indicative of reporting bias at outcome level. However, rather than reporting bias, lack of outcome data should simply be seen as one of the many limitations inherent in studies conducted on patients admitted to the ICU. We factorized potential biases at study level by assessing the methodological quality of the studies, which allowed us to assess the reliability and validity of the data and to weigh the results of each study based on its methodological rigor. Unfortunately, because of the impossibility of calculating the effect sizes in many of the studies included in the review, the risk of publication bias could not be assessed.

\section{Conclusions}

This systematic review provides evidence that adding NMES therapy to usual care is more effective than usual care alone or sham NMES in preventing ICUAW. Nevertheless, there is inconclusive evidence about the effectiveness of NMES for the preservation of muscle mass in ICU patients. The effects of NMES we found were probably underestimated because of the nonstratification of patients according to main diagnosis and disease severity. More studies are needed to explore the long-term effects of NMES therapy during ICU stay on physical function and quality of life in ICU survivors, in order to identify the optimal NMES dosage for ICUAW prevention (both in terms of frequency, intensity and volume), and to describe the feasibility, safety, and cost-effectiveness of NMES in different subpopulations of critically ill patients.

\section{Additional file}

\section{Additional file 1: PRISMA 2009 checklist.}

\section{Abbreviations}

APACHE: Acute physiology and chronic health evaluation; CENTRAL: Cochrane controlled trials register; CINAHL: Cumulative index to nursing and allied health literature; COPD: Chronic obstructive pulmonary disease; ICU: Intensive care unit; ICUAW: Intensive care unit acquired weakness; ITT: Intention-to-treat; MRC: Medical research council; NMES: Neuromuscular electrical stimulation; PEDro: Physiotherapy evidence database; PRISMA: Preferred reporting items for systematic reviews and meta-analyses; RCT: Randomized controlled trial; SAPS: Simplified Acute Physiology Score; SD: Standard deviation; SOFA: Sequential organ failure assessment. 


\section{Competing interests}

The authors declare that they have no competing interests.

\section{Authors' contributions}

NAM and MR made substantial contribution to conception and design of the review. All authors made substantial contribution to data acquisition, analysis, and interpretation. All authors were involved in drafting and critically revising the manuscript. All authors approved the final manuscript.

\section{Acknowledgements}

MR was funded by the Ludvig and Sara Elsass Foundation.

\section{Author details}

${ }^{1}$ Neuromuscular Research Laboratory, Schulthess Clinic, Zurich, Switzerland. ${ }^{2}$ School of Physical and Occupational Therapy, McGill University, Montreal, Canada. ${ }^{3}$ Department of Exercise and Sport Sciences and Department of Neuroscience and Pharmacology, University of Copenhagen, Copenhagen, Denmark. ${ }^{4}$ First Critical Care Department, Evangelismos Hospital, National and Kapodistrian University of Athens, Athens, Greece.

Received: 26 November 2012 Accepted: 19 April 2013

Published: 23 May 2013

\section{References}

1. Latronico N, Bolton CF: Critical illness polyneuropathy and myopathy: a major cause of muscle weakness and paralysis. Lancet Neurol 2011, 10:931-941.

2. Puthucheary Z, Montgomery H, Moxham J, Harridge S, Hart N: Structure to function: muscle failure in critically ill patients. J Physio/ 2010, 588:4641-4648.

3. de Jonghe B, Lacherade JC, Sharshar T, Outin H: Intensive care unit-acquired weakness: risk factors and prevention. Crit Care Med 2009, 37:S309-315.

4. De Jonghe B, Sharshar T, Hopkinson N, Outin H: Paresis following mechanical ventilation. Curr Opin Crit Care 2004, 10:47-52.

5. Griffiths RD, Palmer TE, Helliwell T, MacLennan P, MacMillan RR: Effect of passive stretching on the wasting of muscle in the critically ill. Nutrition 1995, 11:428-432.

6. Reid CL, Campbell IT, Little RA: Muscle wasting and energy balance in critical illness. Clin Nutr 2004, 23:273-280.

7. De Jonghe B, Bastuji-Garin S, Durand MC, Malissin I, Rodrigues P, Cerf C, Outin H, Sharshar T: Respiratory weakness is associated with limb weakness and delayed weaning in critical illness. Crit Care Med 2007, 35:2007-2015.

8. Edbrooke DL, Minelli C, Mills GH, lapichino G, Pezzi A, Corbella D, Jacobs P, Lippert A, Wiis J, Pesenti A, et al: Implications of ICU triage decisions on patient mortality: a cost-effectiveness analysis. Crit Care 2011, 15:R56.

9. Leijten FS, Harinck-de Weerd JE, Poortvliet DC, de Weerd AW: The role of polyneuropathy in motor convalescence after prolonged mechanical ventilation. JAMA 1995, 274:1221-1225.

10. Nanas S, Kritikos K, Angelopoulos E, Siafaka A, Tsikriki S, Poriazi M, Kanaloupiti D, Kontogeorgi M, Pratikaki M, Zervakis D, et al: Predisposing factors for critical illness polyneuromyopathy in a multidisciplinary intensive care unit. Acta Neuro/ Scand 2008, 118:175-181.

11. Herridge MS, Tansey CM, Matte A, Tomlinson G, Diaz-Granados N, Cooper A, Guest CB, Mazer CD, Mehta S, Stewart TE, et al: Functional disability 5 years after acute respiratory distress syndrome. N Engl J Med 2011, 364:1293-1304.

12. Fletcher SN, Kennedy DD, Ghosh IR, Misra VP, Kiff K, Coakley JH, Hinds CJ: Persistent neuromuscular and neurophysiologic abnormalities in longterm survivors of prolonged critical illness. Crit Care Med 2003, 31:1012-1016.

13. Burtin C, Clerckx B, Robbeets C, Ferdinande P, Langer D, Troosters T, Hermans G, Decramer M, Gosselink R: Early exercise in critically ill patients enhances short-term functional recovery. Crit Care Med 2009, 37:2499-2505.

14. Schweickert WD, Pohlman MC, Pohlman AS, Nigos C, Pawlik AJ, Esbrook CL, Spears L, Miller M, Franczyk M, Deprizio D, et al: Early physical and occupational therapy in mechanically ventilated, critically ill patients: a randomised controlled trial. Lancet 2009, 373:1874-1882.
15. Thomsen GE, Snow GL, Rodriguez L, Hopkins RO: Patients with respiratory failure increase ambulation after transfer to an intensive care unit where early activity is a priority. Crit Care Med 2008, 36:1119-1124.

16. Puthucheary Z, Harridge $S$, Hart N: Skeletal muscle dysfunction in critical care: Wasting, weakness, and rehabilitation strategies. Crit Care Med 2010, 38:5676-S682

17. Needham DM, Truong AD, Fan E: Technology to enhance physical rehabilitation of critically ill patients. Crit Care Med 2009, 37:\$436-441.

18. Truong AD, Fan E, Brower RG, Needham DM: Bench-to-bedside review: mobilizing patients in the intensive care unit-from pathophysiology to clinical trials. Crit Care 2009, 13:216.

19. Stevens RD, Hart N, de Jonghe B, Sharshar T: Weakness in the ICU: a call to action. Crit Care 2009, 13:R161.

20. Lee CM, Fan E: ICU-acquired weakness: what is preventing its rehabilitation in critically ill patients? BMC Med 2012, 10:115.

21. Maffiuletti NA: Physiological and methodological considerations for the use of neuromuscular electrical stimulation. Eur J App/ Physio/ 2010, 110:223-234.

22. Roig $M$, Reid WD: Electrical stimulation and peripheral muscle function in COPD: a systematic review. Respir Med 2009, 103:485-495.

23. Gibson JN, Smith K, Rennie MJ: Prevention of disuse muscle atrophy by means of electrical stimulation: maintenance of protein synthesis. Lancet 1988, 2:767-770.

24. Gerovasili V, Tripodaki E, Karatzanos E, Pitsolis T, Markaki V, Zervakis D, Routsi C, Roussos C, Nanas S: Short-term systemic effect of electrical muscle stimulation in critically ill patients. Chest 2009, 136:1249-1256.

25. Gerovasili V, Stefanidis K, Vitzilaios K, Karatzanos E, Politis P, Koroneos A, Chatzimichail A, Routsi C, Roussos C, Nanas S: Electrical muscle stimulation preserves the muscle mass of critically ill patients: a randomized study. Crit Care 2009, 13:R161.

26. Laghi F, Jubran A: Treating the septic muscle with electrical stimulations. Crit Care Med 2011, 39:585-586.

27. Kho ME, Truong AD, Brower RG, Palmer JB, Fan E, Zanni JM, Ciesla ND, Feldman DR, Korupolu R, Needham DM: Neuromuscular electrical stimulation for intensive care unit-acquired weakness: protocol and methodological implications for a randomized, sham-controlled, phase II trial. Phys Ther 2012, 92:1564-1579.

28. Maddocks M, Gao W, Higginson IJ, Wilcock A: Neuromuscular electrical stimulation for muscle weakness in adults with advanced disease. Cochrane Database Syst Rev 2011, 11, CD009419.

29. Moher D, Liberati A, Tetzlaff J, Altman DG: Preferred reporting items for systematic reviews and meta-analyses: the PRISMA statement. PLoS Med 2009, 6:e1000097.

30. de Morton NA: The PEDro scale is a valid measure of the methodological quality of clinical trials: a demographic study. Aust J Physiother 2009, 55:129-133.

31. Maher CG, Sherrington C, Herbert RD, Moseley AM, Elkins M: Reliability of the PEDro scale for rating quality of randomized controlled trials. Phys Ther 2003, 83:713-721.

32. Roig M, Shadgan B, Reid WD: Eccentric exercise in patients with chronic health conditions: a systematic review. Physiother Can 2008, 60:146-160.

33. van Tulder M, Furlan A, Bombardier C, Bouter L: Updated method guidelines for systematic reviews in the cochrane collaboration back review group. Spine (Phila Pa 1976) 2003, 28:1290-1299.

34. Field A: Discovering statistics using SPSS. 2nd edition. London: SAGE; 2005:156.

35. Karatzanos E, Gerovasili V, Zervakis D, Tripodaki ES, Apostolou K, Vasileiadis I, Papadopoulos E, Mitsiou G, Tsimpouki D, Routsi C, et al: Electrical muscle stimulation: an effective form of exercise and early mobilization to preserve muscle strength in critically ill patients. Crit Care Res Pract 2012, 2012:432752.

36. Routsi C, Gerovasili V, Vasileiadis I, Karatzanos E, Pitsolis T, Tripodaki E, Markaki V, Zervakis D, Nanas S: Electrical muscle stimulation prevents critical illness polyneuromyopathy: a randomized parallel intervention trial. Crit Care 2010, 14:R74.

37. Hozo SP, Djulbegovic B, Hozo I: Estimating the mean and variance from the median, range, and the size of a sample. BMC Med Res Methodol 2005, $5: 13$.

38. Cohen J: Statistical methods for meta-analysis. San Diego: Academic Press; 1998.

39. Rodriguez P, Bonelli I, Setten M, Attie S, Maskin P, Kozima S, Valentini R: Electric neuromuscular stimulation for prevention of ICU-acquired paresis in patients with severe sepsis. Intensive Care Med 2009, 35:133-133. 
40. Schneider JB, Weber-Carstens S, Bierbrauer J, Marg A, Olbricht C, Hasani H, Spuler S: Electrical muscle stimulation in early severe critical illness prevents type 2 fiber atrophy. Neuromuscul Disord 2011, 21:744-744.

41. Meesen RL, Dendale P, Cuypers K, Berger J, Hermans A, Thijs H, Levin O: Neuromuscular electrical stimulation as a possible means to prevent muscle tissue wasting in artificially ventilated and sedated patients in the intensive care unit: a pilot study. Neuromodulation 2010 13:315-321.

42. Bouletreau P, Patricot MC, Saudin F, Guiraud M, Mathian B: Effects of intermittent electrical stimulations on muscle catabolism in intensive care patients. JPEN J Parenter Enteral Nutr 1987, 11:552-555.

43. Abdellaoui A, Prefaut C, Gouzi F, Couillard A, Coisy-Quivy M, Hugon G, Molinari N, Lafontaine T, Jonquet O, Laoudj-Chenivesse D, et al: Skeletal muscle effects of electrostimulation after COPD exacerbation: a pilot study. Eur Respir J 2011, 38:781-788.

44. Gruther W, Kainberger F, Fialka-Moser V, Paternostro-Sluga T, Quittan M, Spiss C, Crevenna R: Effects of neuromuscular electrical stimulation on muscle layer thickness of knee extensor muscles in intensive care unit patients: a pilot study. J Rehabil Med 2010, 42:593-597.

45. Poulsen JB, Moller K, Jensen CV, Weisdorf S, Kehlet H, Perner A: Effect of transcutaneous electrical muscle stimulation on muscle volume in patients with septic shock. Crit Care Med 2011, 39:456-461.

46. Rodriguez PO, Setten M, Maskin LP, Bonelli I, Vidomlansky SR, Attie S, Frosiani SL, Kozima S, Valentini R: Muscle weakness in septic patients requiring mechanical ventilation: protective effect of transcutaneous neuromuscular electrical stimulation. J Crit Care 2012, 27:e311-318.

47. Zanotti E, Felicetti G, Maini M, Fracchia C: Peripheral muscle strength training in bed-bound patients with COPD receiving mechanical ventilation: effect of electrical stimulation. Chest 2003, 124:292-296.

48. Landis JR, Koch GG: The measurement of observer agreement for categorical data. Biometrics 1977, 33:159-174.

49. Rabe KF, Hurd S, Anzueto A, Barnes PJ, Buist SA, Calverley P, Fukuchi Y, Jenkins C, Rodriguez-Roisin $R$, van Weel $C$, et al: Global strategy for the diagnosis, management, and prevention of chronic obstructive pulmonary disease: GOLD executive summary. Am J Respir Crit Care Med 2007, 176:532-555

50. Maffiuletti NA, Herrero AJ, Jubeau M, Impellizzeri FM, Bizzini M: Differences in electrical stimulation thresholds between men and women. Ann Neurol 2008, 63:507-512.

51. Bednarik J, Vondracek P, Dusek L, Moravcova E, Cundrle I: Risk factors for critical illness polyneuromyopathy. J Neurol 2005, 252:343-351.

52. Harper NJ, Greer R, Conway D: Neuromuscular monitoring in intensive care patients: milliamperage requirements for supramaximal stimulation. Br J Anaesth 2001, 87:625-627.

53. Maffiuletti NA, Minetto MA, Farina D, Bottinelli R: Electrical stimulation for neuromuscular testing and training: state-of-the art and unresolved issues. Eur J Appl Physiol 2011, 111:2391-2397.

54. Vivodtzev I, Debigare R, Gagnon P, Mainguy V, Saey D, Dube A, Pare ME, Belanger M, Maltais F: Functional and muscular effects of neuromuscular electrical stimulation in patients with severe COPD: a randomized clinical trial. Chest 2012, 141:716-725

55. Napolis LM, Dal Corso S, Neder JA, Malaguti C, Gimenes AC, Nery LE: Neuromuscular electrical stimulation improves exercise tolerance in chronic obstructive pulmonary disease patients with better preserved fat-free mass. Clinics (Sao Paulo) 2011, 66:401-406.

56. Vanderthommen M, Duchateau J: Electrical stimulation as a modality to improve performance of the neuromuscular system. Exerc Sport Sci Rev 2007, 35:180-185.

57. Gobbo M, Gaffurini P, Bissolotti L, Esposito F, Orizio C: Transcutaneous neuromuscular electrical stimulation: influence of electrode positioning and stimulus amplitude settings on muscle response. Eur J Appl Physiol 2011, 111:2451-2459.

58. Sapega AA: Muscle performance evaluation in orthopaedic practice. J Bone Joint Surg Am 1990, 72:1562-1574.

59. Maffiuletti NA: Assessment of hip and knee muscle function in orthopaedic practice and research. J Bone Joint Surg Am 2010, 92:220-229.

60. Gandevia SC: Spinal and supraspinal factors in human muscle fatigue. Physiol Rev 2001, 81:1725-1789.

61. Man WD, Moxham J, Polkey MI: Magnetic stimulation for the measurement of respiratory and skeletal muscle function. Eur Respir J 2004, 24:846-860.
62. Rutkove SB: Electrical impedance myography: Background, current state, and future directions. Muscle Nerve 2009, 40:936-946.

63. Chuang LL, Wu CY, Lin KC: Reliability, validity, and responsiveness of myotonometric measurement of muscle tone, elasticity, and stiffness in patients with stroke. Arch Phys Med Rehabil 2012, 93:532-540.

64. Pisot R, Narici MV, Simunic B, De Boer M, Seynnes O, Jurdana M, Biolo G, Mekjavic IB: Whole muscle contractile parameters and thickness loss during 35-day bed rest. Eur J Appl Physiol 2008, 104:409-414.

65. Deem S: Intensive-care-unit-acquired muscle weakness. Respir Care 2006, 51:1042-1052. discussion 1052-1043.

66. Hortobagyi T, Maffiuletti NA: Neural adaptations to electrical stimulation strength training. Eur J App/ Physio/ 2011, 111:2439-2449.

doi:10.1186/1741-7015-11-137

Cite this article as: Maffiuletti et al.: Neuromuscular electrical stimulation for preventing skeletal-muscle weakness and wasting in critically ill patients: a systematic review. BMC Medicine 2013 11:137.

\section{Submit your next manuscript to BioMed Central and take full advantage of:}

- Convenient online submission

- Thorough peer review

- No space constraints or color figure charges

- Immediate publication on acceptance

- Inclusion in PubMed, CAS, Scopus and Google Scholar

- Research which is freely available for redistribution 